\title{
A Morphological Study on the Melanophores of Two Mormyrid Fish, Marcusenius isidori and $M$. longianalis
}

\author{
Kouichi YoshIZAKI* \\ (Received April 28, 1981)
}

\begin{abstract}
A morphological investigation was done on the epidermal and dermal melanophores of two mormyrid fish, Marcusenius isidori and $M$. longianalis.

The epidermal melanophores were located in the outer and middle layers of the epidermis as well as in the inner layer. The dermal melanophores occurred just beneath the basal lamina and in the deeper part of the dermis. The dermal melanophores of $M$. longianalis had sometimes elongated melanosomes as well as ovoid-shaped ones. The premelanosomes of the epidermal melanophores had a doughnut-like inner structure. The premelanosomes of the dermal melanophores also had a doughnut-like inner structure in addition to a striped inner structure. The melanophores of Marcusenius isidori and $\boldsymbol{M}$. longianalis possess the basic characteristics common to other vertebrates, and they resemble closely those of other mormyrid fish, Gnathonemus petersii, and other fish.
\end{abstract}

Fish have several chromatophores such as melanophores, xanthophores, and iridophores. These chromatophores have received great attention as they are involved in color patterns and in color changes characterizing many fish types. Among fish chromatophores, melanophores are very important in these phenomena. Therefore, in addition to physiological studies, ${ }^{1,2)}$ many morphological observations have been done on fish melanophores. ${ }^{3-71}$

It is well-known that mormyrid fish are weakly electric fish and have special electroreceptors in their epidermis. HARDER ${ }^{8)}$ reported the ultrastructure of the electroreceptor epidermis of a mormyrid fish Gnathonemus petersii, but no description was given on its melanophore. In the course of the morphological study of fish melanophores, I found out the melanophores in the epidermis as well as in the dermis of this mormyrid fish. There were few morphological studies on the epidermal melanophores in fish, ${ }^{4-81}$ although in other vertebrates $^{\theta-11}$ morphological characteristics of the epidermal melanophores were clarified. In the previous paper," I described the ultrastructures of the epidermal and dermal melanophores of this mormyrid fish. The aim of this work is to examine the morphological characteristics of the epidermal and dermal melanophores of other mormyrid fish.

\section{Materials and Methods}

Each two specimens of Marcusenius isidori and Marcusenius longianalis, $78-100 \mathrm{~mm}$ in total length, were obtained from a commercial supplier. The skin of the fish was cut in small pieces, and fixed in cold $2.5 \%$ glutaraldehyde containing Millonig's phosphate buffer solution, and post-fixed in $2 \%$ osmium tetroxide containing the same buffer solution. After dehydrating the pieces by passing them through graded ethanol, they were embedded in Quetol 812. Thin sections were made by a Soval Porter-Blum MT-1 ultramicrotome. The sections were double stained with a $2 \%$ aqueous solution of uranyl acetate and a lead staining solution, ${ }^{12}$ and examined with a JEM-100CX electron microscope. I made semi-thin sections from the blocks embedded in the epoxy resin for light microscopic observations. These sections were stained with $0.5 \%$ toluidine blue containing Sörensen's phosphate buffer solution.

\section{Results}

The epidermis of Marcusenius isidori and $M$. longianalis could be divided morphologically into three layers: outer, middle, and inner layers (Figs. 1a \& 2a). The outer layer consisted of the flat epidermal cells. The middle layer consisted of the very flat epidermal cells which attached closely to the adjacent cells. The inner layer consisted

* Fisheries Laboratory, Faculty of Agriculture, Nagoya University, Chikusa, Nagoya 464, Japan (吉崘幸一:

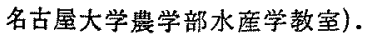


Table 1. Morphological characteristics of melanophores in mormyrid fish

\begin{tabular}{|c|c|c|c|c|}
\hline & & & Marcusenius isidori & Marcusenius longianalis \\
\hline \multirow{2}{*}{\multicolumn{2}{|c|}{ Epidermal melanophore }} & Shape & Ovoid (with fine and short processes) & Ovoid (with some processes) \\
\hline & & Size & $6 \times 16 \mu \mathrm{m}$ & $7 \times 15 \mu \mathrm{m}$ \\
\hline \multirow{2}{*}{\multicolumn{2}{|c|}{ Nucleus }} & Shape & Irregular (deep indentation) & Irregular (deep indentation) \\
\hline & & Size & $4 \times 10 \mu \mathrm{m}$ & $4 \times 10 \mu \mathrm{m}$ \\
\hline \multirow[t]{3}{*}{ Organelle } & Melanosome & Shape & Ovoid or round & Ovoid \\
\hline & & Size & $0.8 \times 1 \mu \mathrm{m}$ & $0.5 \times 0.7 \mu \mathrm{m}$ \\
\hline & Microfilament & Diameter & $70 \AA$ & $70 \AA$ \\
\hline \multirow{2}{*}{\multicolumn{2}{|c|}{ Dermal melanophore }} & Shape & Dendritic & Dendritic \\
\hline & & Size & $\begin{array}{l}300-400 \mu \mathrm{m} \\
\text { (perikaryon: } 15-25 \mu \mathrm{m} \text { ) }\end{array}$ & $\begin{array}{l}300-400 \mu \mathrm{m} \\
\text { (perikaryon: } 15-20 \mu \mathrm{m} \text { ) }\end{array}$ \\
\hline \multirow{2}{*}{\multicolumn{2}{|c|}{ Nucleus }} & Shape & Ovoid & Ovoid \\
\hline & & Size & $10 \times 30 \mu \mathrm{m}$ & $10 \times 30 \mu \mathrm{m}$ \\
\hline \multirow[t]{4}{*}{ Organelle } & Melanosome & Shape & Ovoid & Ovoid or elongated ovoid \\
\hline & & Size & $0.5 \times 0.8 \mu \mathrm{m}$ & $0.5 \times 0.7-0.4 \times 1.3 \mu \mathrm{m}$ \\
\hline & Microfilament & Diameter & $80 \AA$ & $80 \AA$ \\
\hline & Microtubule & Diameter & $220 \AA$ & $250 \AA$ \\
\hline
\end{tabular}

of the ovoid epidermal cells. The dermis of Marcusenius isidori and $M$. longianalis consisted of the loose connective tissue. The obvious components of their dermis were fibroblast, capillary, boundle of nerve fiber, collagenous fiber bundle, and melanophore.

Melanophores of Marcusenius isidori and $M$. longianalis were observed in both the epidermis and the dermis. The epidermal melanophores appeared infrequently in the skin of these species. On the other hand, the dermal melanophores appeared abundantly in the skin of these species. Morphological characteristics of their two melanophores were summarized in Table 1. The distribution patterns of their two melanophores were as follows. The epidermal melanophores were most frequently found in the inner layer of the epidermis, but sometimes they appeared in the middle and outer layers of the epidermis (Figs. 1a \& 2a). On the other hand, the dermal melanophores located mostly just beneath the basal lamina forming one or more layers, they occasionally scattered in the deeper part of the dermis (Figs. 1a \& 2a).

The epidermal melanophores of Marcusenius isidori and $M$. longianalis were identified by membrane-bound melanosomes in their cytoplasm (Figs. $3 \& 5$ ). The epidermal melanophores were frequently away from the adjacent epidermal cells at a relatively wide intercellular space (Fig. 3). The epidermal melanophores had short, fine cytoplasmic processes, and adhered with the cytoplasmic processes to the adjacent epidermal cells (Fig. 4). A specialization of the surfaces of the epidermal melanophores for cell-to-cell attachment was not observed (Figs. $3 \& 5$ ). The nuclei of the epidermal melanophores were very irregular in shape, and sometimes had deep indentations (Figs. $3 \& 5$ ). Their chromatins were mostly distributed in a reticular pattern, and their nucleoli could not be observed. Although the melanosomes of the epidermal melanophores of Marcusenius isidori were slightly different in size from those of Marcusenius longianalis (Table 1), the melanosomes of the epidermal melanophores of these two mormyrid fish were similar in shape to each other (Figs. $4 \& 6$ ). The majority of the melanosomes were fully melanized, and their internal structures were hardly distinguishable (Figs. 4 \& 6). However, some of melanosomes exhibited a premelanosomal inner structure. These premelanosomes were $0.1 \times 0.2-0.2 \times 0.3 \mu \mathrm{m}$ and were smaller than the melanosomes. The premelanosomes of the epidermal melanophores had a doughnut-like inner structure, that is, they were electron dense near the limiting membrane and were electron lucent in the center (Fig. 6). Other obvious organelles of the epidermal melanophores of Marcusenius isidori and $M$. longianalis were mitochondrion, Golgi-apparatus, smooth-surfaced endoplasmic reticulum, free ribosome, and microfilament.

The dermal melanophores of Marcusenius isidori and $M$. longianalis were identified by membranebound melanosomes and by branching cytoplasmic processes (Figs. 1b \& 2b). The sizes of the perikaria were not greatly different from those of the epidermal melanophores (Table 1). The nuclei of the dermal melanophores were ovoid in shape, 


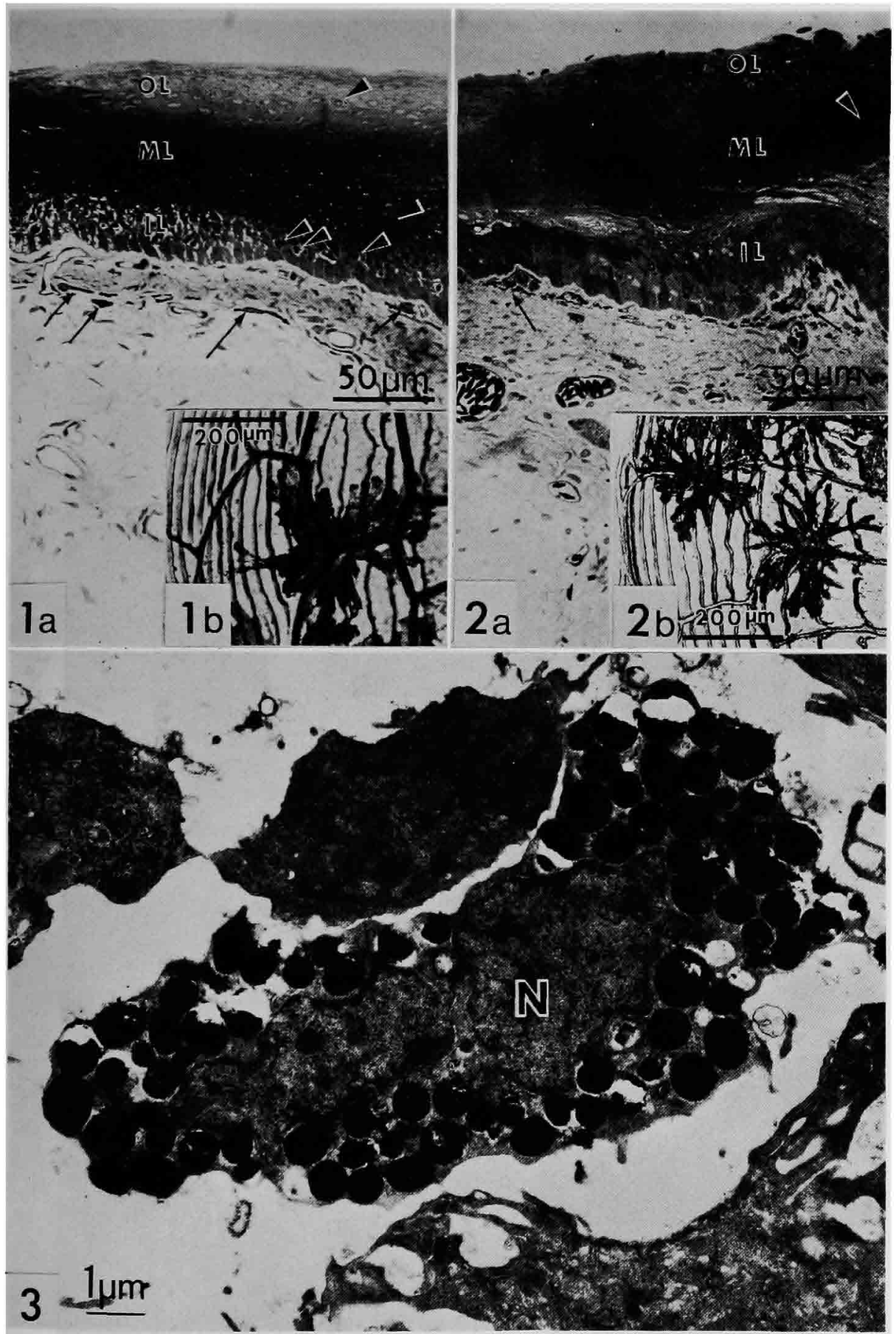

Fig. 1a. Photomicrograph of the skin of Marcusenius isidori showing epidermal melanophores (Arrow heads) and dermal melanophores (Arrows). Toluidine blue staining.

Fib. 1b. Photomicrograph of the scale preparation of $M$. isidori.

Fig. 2a. Photomicrograph of the skin of Marcusenius longianalis showing a epidermal melanophore (Arrow head) and dermal melanophores (Arrows). Toluidine blue staining.

Fig. 2b. Photomicrograph of the scale preparation of $M$. longianalis.

Fig. 3. Electron micrograph of a epidermal melanophore of $M$. isidori.

EMs: Elongated melanosome IL: Inner layer ML: Middle layer Ms: Melanosome Mt: Microtubule N: Nucleus OL: Outer layer Pm: Premelanosome PV: Pinocytotic vesicle 


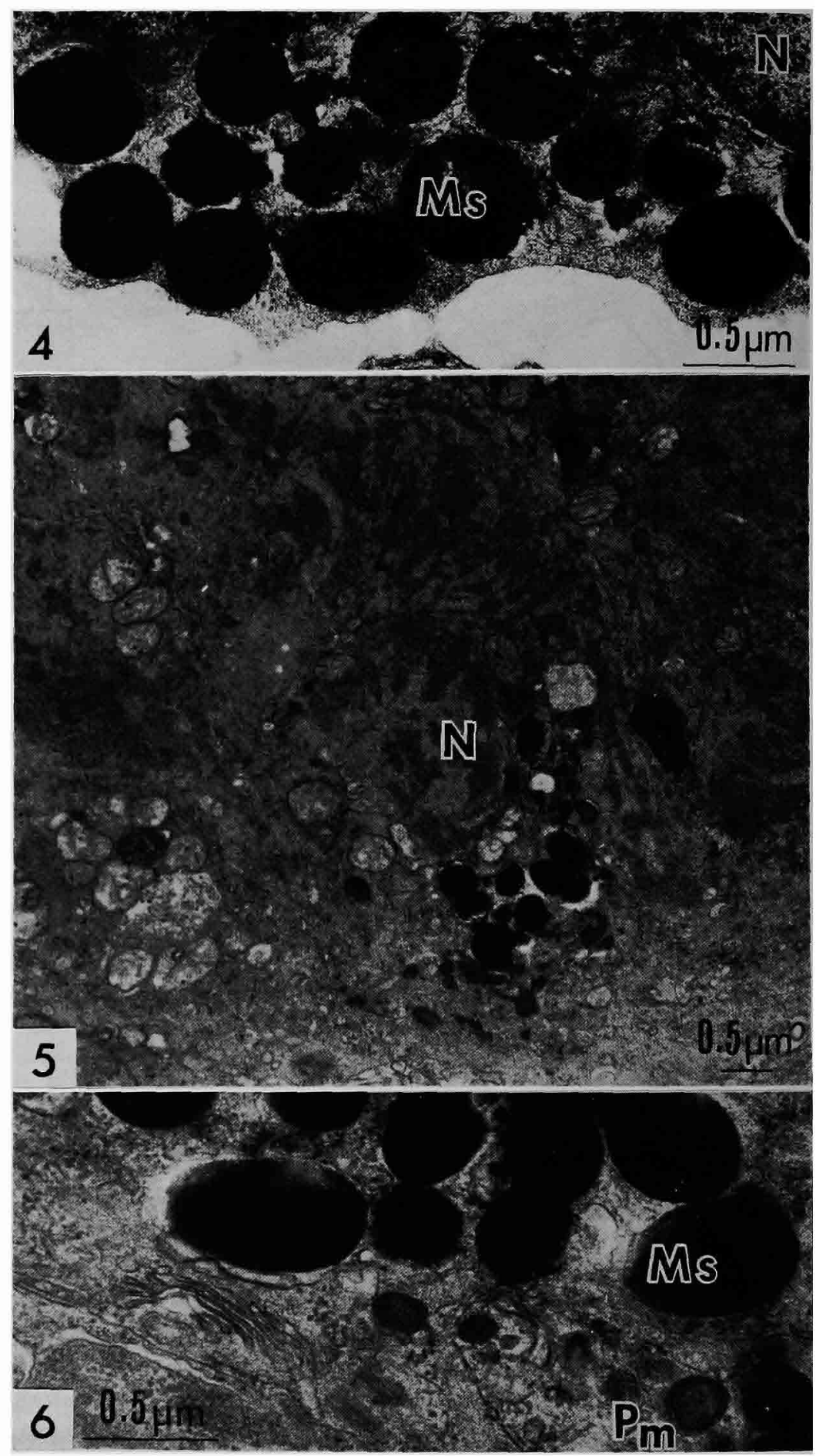

Fig. 4. Detail of Fig. 3 showing melanosomes.

Fig. 5. Electron micrograph of a epidermal melanophore of $M$. longianalis.

Fig. 6. Part of a epidermal melanophore of $M$. longianalis showing premelanosomes which have a doughnut-like inner structure. 


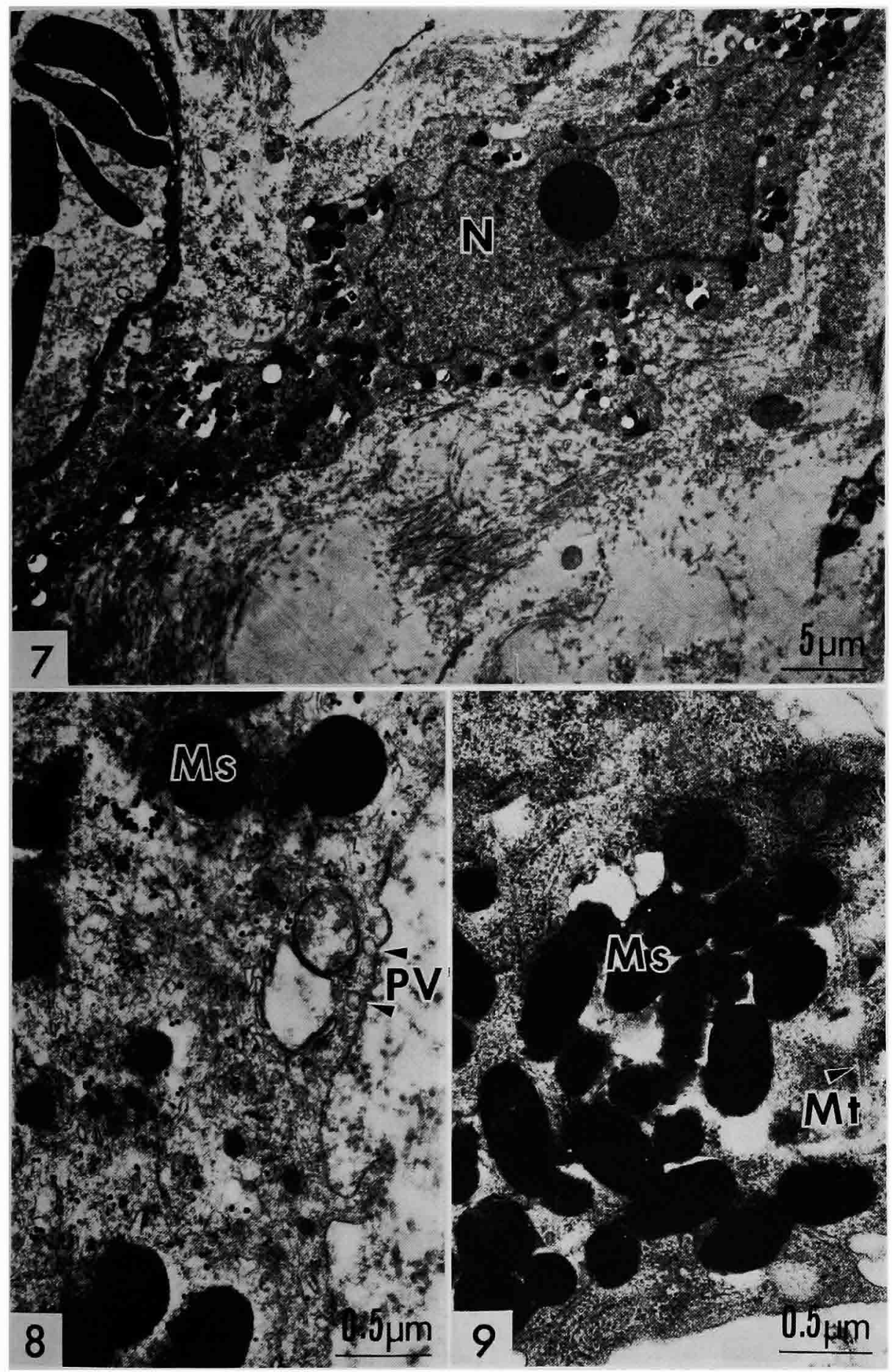

Fig. 7. Electron micrograph of a dermal melanophore of $M$. isidori.

Fig. 8. Detail of Fig. 7 containing many melanosomes in the cytoplasm.

Fig. 9. Part of a dermal melanophore of $M$. isidori showing melanosomes and microtubules. 


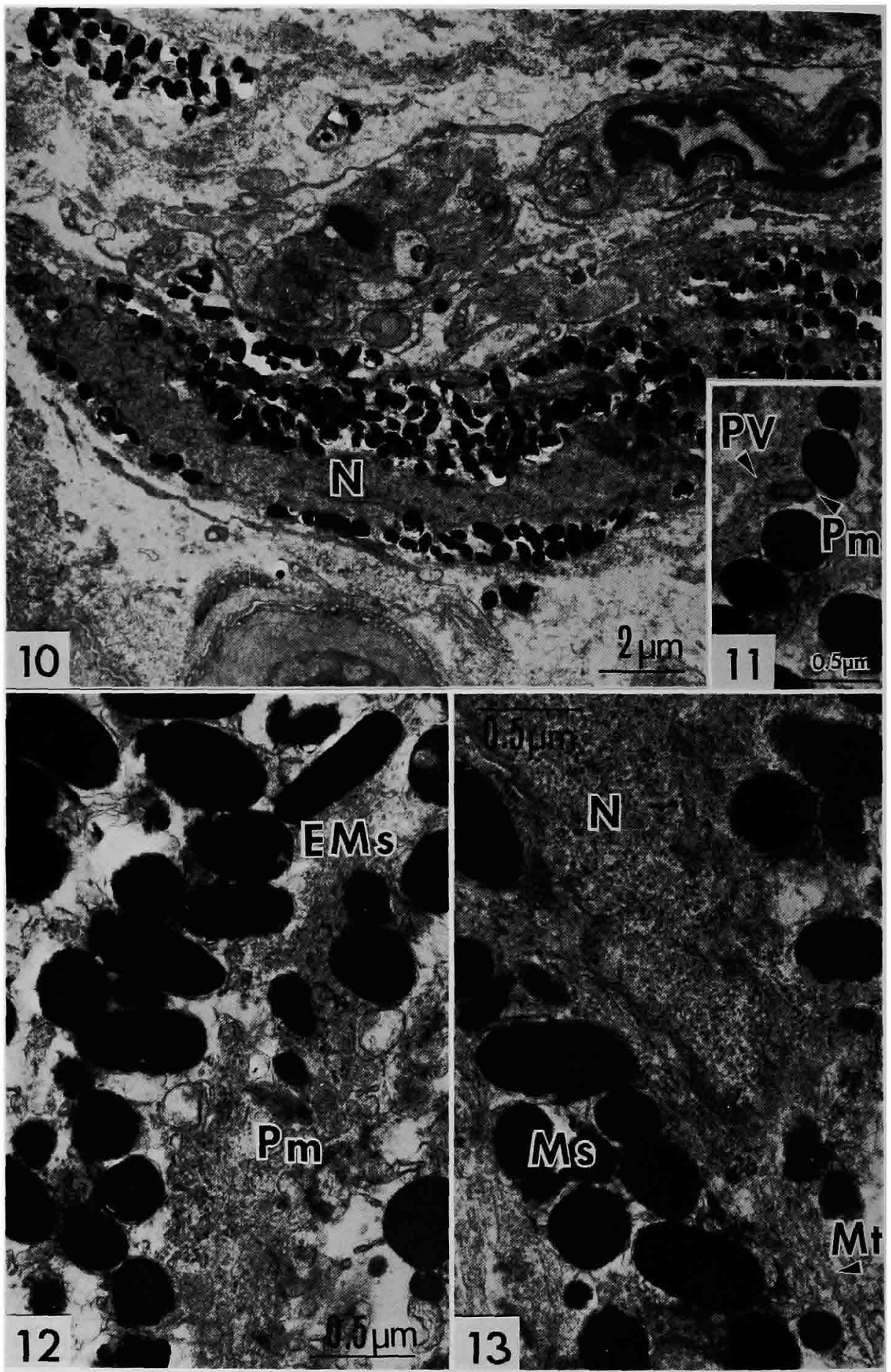

Fig. 10. Electron micrograph of a dermal melanophore of $M$. longianalis.

Fig. 11. Detail of Fig. 10 containing a premelanosome which have a doughnut-like inner structure. Pinocytotic vesicles are observed at the cell membrane.

Fig. 12. Part of a dermal melanophore of $M$. longianalis showing an elongated melanosome and a premelanosome which have a striped inner structure

Fig. 13. Part of a dermal melanophore of $M$. longianalis containing microtubules. 
and their outlines were relatively smooth (Figs. 7 \& 10). Their chromatins were distributed mostly as uniform and minute particles. The nucleoli of the dermal melanophores were sometimes present (Fig. 7). Pinocytotic vesicles were observed all around the cell membrane, and they were round in shape, measuring approximately $0.08 \mu \mathrm{m}$ in diameter (Figs. 8 \& 11). The melanosomes of the dermal melanophores of Marcusenius isidori and $M$. longianalis were mostly about the same in shape and size as those of other fish. ${ }^{9-7)}$ However, the melanosomes of the dermal melanophores of Marcusenius longianalis were sometimes elongated ovoid in shape (Fig. 12). Although most of the melanosomes of the dermal melanophores were fully melanized, some of them exhibited a premelanosomal inner structures. These premelanosomes were $0.1 \times 0.3-0.2 \times 0.4 \mu \mathrm{m}$ and were smaller than the melanosomes. Some of these premelanosomes had a doughnut-like inner structure similar to those of the epidermal melanophores (Fig. 11). But, premelanosomes of the dermal melanophores had mostly a striped inner structure, these stripes were approximately $50 \AA$ in thickness (Fig. 12). Microtubules and microfilaments appeared in their cytoplasm (Figs. $9 \& 13$ ). The microtubules of Marcusenius longianalis were somewhat thicker than those of Marcusenius isidori (Table 1). Other obvious organelles of their dermal melanophores were mitochondrion, Golgi-apparatus, smooth surfaced endoplasmic reticulum, and free ribosome.

\section{Discussion}

Although the epidermal melanophores and the dermal ones of Marcusenius isidori and $M$. longianalis exhibit basically the same structural features as those of other fish, ${ }^{3-7)}$ some of their characteristics deserve comment.

It was described in lungfish ${ }^{4-81}$ that the epidermal melanophores located in the intermediate level of the epidermis. In the previous paper, ${ }^{7)}$ I reported in Gnathonemus petersit that the epidermal melanophores appeared in the inner layer of the epidermis. But, in the present observation, the epidermal melanophores of Marcusenius isidori and $M$. longianalis located in the outer and the middle layers as well as in the inner layer. It is reported in reptiles ${ }^{10 /}$ and in mammals ${ }^{11)}$ that the epidermal melanophores are located among the basal layer of the epidermis. It is stated in vertebrates ${ }^{\theta 1}$ that the epidermal melanophores invade the epidermis before the differentiation from their chromatoblasts. Therefore, I consider that these distri- bution patterns show the occurrence of the upward migration of the epidermal melanophores in the lungfish ${ }^{4-8}$ ) and the mormyrid fish used in the present observation. In spite of the close arrangement of the epidermal cells in the middle layer of Marcusenius isidori and $M$. longianalis, the epidermal melanophores appeared in the middle layer and even in the outer layer in addition to in the inner layer of the epidermis. Therefore, it can be considered that the ability of the migration of the epidermal melanophores of Marcusenius isidori and $M$. longianalis is relatively high.

The dermal melanophores of fish are sometimes classified into a macromelanophore and a micromelanophore." The macromelanophores are approximately $300 \mu \mathrm{m}$ in diameter, and the micromelanophores are approximately $100 \mu \mathrm{m}$ in diameter. Accordingly, it is concluded that the dermal melanophores of Marcusenius isidori and $M$. longianalis belong to so-called macromelanophores as reported in the previous paper ${ }^{7}$ using Gnathonemus petersii, although the dermal melanophores of Marcusenius isidori and $M$. longianalis are slightly larger than those of Gnathonemus petersii. It is conceivable that the sizes of the perikaria of the dermal melanophores are similar to those of the epidermal melanophores of these two mormyrid fish in the present observation, since it is stated in vertebrates ${ }^{\text {' }}$ that both the epidermal melanophores and the dermal ones originate embryonically from the same neural crest ectoderm.

Two types of the color change are generally recognized in fish $^{2}$ : physiological and morphological color changes. The former is based on the displacement of the melanosomes in the melanophores. On the contrary, the latter is based on the increase or decrease of the number of the melanophores. It is possible that the epidermal melanophores and the dermal ones participate in the morphological color change in Marcusenius isidori and $M$. longianalis. It is said in other fish ${ }^{3 /}$ that the microtubules take part in the displacement of the melanosomes. Because the epidermal melanophores of a coelacanth possessed the microtubules in the cytoplasm, LAMER and $\mathrm{CHAVIN}^{\mathrm{B} 1}$ assumed that the epidermal melanophores of this fish participated in the physiological color change. Owing to the existence of the microtubules, the dermal melanophores of Marcusenius isidori and $M$. longianalis assume to participate in the physiological color change similar to those of other fish. ${ }^{3-71}$ On the other hand, the microtubule was not observed in the epidermal melanophores 
of Marcusenius isidori and M. longianalis. Therefore, it can be considered that the epidermal melanophores of these mormyrid fish do not participate in the physiological color change.

In human, ${ }^{191}$ the melanosomes are transferred to the keratinocytes which construct their epidermis It is also stated in other fish ${ }^{4-61}$ that the epidermal melanophores produce the melanosomes and transfer to other epidermal cells. In the previous paper, ${ }^{7}$ I reported that the transference of the melanosomes seemed to occur in the epidermis of Gnathonemus petersii, judging from the existence of the epidermal cells which contained melanosomes in their cytoplasm. Some of the epidermal melanophores of Marcusenius longianalis are suggestive of melanin-synthesis owing to their morphological characteristics. However, it is not certain whether the transference of the melanosomes occur in the epidermis of Marcusenius longianalis or not, because the features showing the transference of the melanosomes are not observed. I consider that more detailed examination is necessary in order to clarify this problem.

Although there is mostly no remarkable difference in shape and size of the melanosomes between the epidermal and dermal melanophores, the elongated melanosomes are observed in the dermal melanophores of Marcusenius longianalis. Such elongated melanosomes were already described in the melanophores of other vertebrates. ${ }^{11,14}$ In fish, the elongated melanosomes are well known in the pigmented epithelial cells of retina. ${ }^{151}$ But, the elongated melanosome is uncommon in the skin melanophore of fish, and is hitherto known only in the epidermal melanophores of one species of lungfish." Biological significance of the elongated melanosomes remains unresolved.

Finally, judging from the inner structure of the premelanosome of Marcusenius isidori and $M$. longianalis, it can be considered that the melanosomes develop mostly through the stage of the striped inner structure, as already reported in other fish $^{41}$ and vertebrates. ${ }^{44,16)}$ The doughnut-like inner structure detected in the present observation has not been reported in other fish as well as in other vertebrates. Various processes in the melanosome development are suggested by the present observation that two different inner structures are recognizable, although whether or not the dough- nut-like inner structure is unique to the present mormyrid fish is the problem for a future study.

\section{Acknowledgements}

I wish to thank Professor M. OGUR, Faculty of Agriculture, Nagoya University, for his critical reading of the manuscript and Mrs. K. KogA for typing the manuscript. I am also indebted to Mr. M. HaYashi, Yokosuka City Museum, for the identification of the mormyrid fish.

\section{References}

1) G.H. PARKer: Animal Colour Changes and their Neurohumours, Cambridge Univ. Press, Cambridge, 1948, pp. 108-175.

2) R. Fuנn: in "Fish Physiology" (ed. by W.S. Hoar and D. J. Randall), Vol. 3, Acad. Press, New York, 1969, pp. 307-353.

3) L. Green: Proc. Nat. Acad. Sci., 59, 1179-1186 (1968).

4) H. Imaki and W. Chavin: Cell Tiss. Res., 158, 363-373 (1975).

5) H. Imaki and W. Chavin: Cell Tiss. Res., 158, 375-389 (1975)

6) H. I. Lamer and W. Chavin: Cell Tiss. Res., 163, 383-394 (1975).

7) K. Yoshizaki and T. Tamura: Bull. Japan. Soc. Sci. Fish., 45, 305-311 (1979).

8) W. HARDER: Z. Zellforsch., 114, 262-270 (1971).

9) J. T. Bagnara and M. E. HadleY: Chromatophores and Color Change, Prentice-Hall Inc., Englewood Cliffs, 1973, pp. 58-73.

10) P. Drochmans: J. Biophys. Biochem. Cytol., 8, 165-180 (1960).

11) J. T. Bagnara, W. Ferris, W. A. Turner JR., and J. D. TAYLOR: Develop. Biol., 64, 149-163(1978).

12) T. SATo: J. Electron Microscopy, 17, 158-159 (1968).

13) T. B. FitzPatrick, Y. Hori, K. TOdA, S. KINEBUCHI, and G. SzABó: in "Biology of Normal and Abnormal Melanocytes" (ed. by T. Kawamura, T. B. Fitzpatrick and M. SeiJ), Tokyo Univ. Press, Tokyo, 1971, pp. 369-401.

14) K. Jimbow and A. KukitA: in "Biology of Normal and Abnormal Melanocytes" (ed. by T. Kawamura, T. B. Fitzpatrick and M. Seisi), Tokyo Univ. Press, Tokyo, 1971, pp. 171-193.

15) H. J. ARnott, J. A. C. Nicol, and C. W. QuerFELD: Proc, R. Soc. Lond. B., 180, 247-271 (1972).

16) A. S. BreathNACH and S. V. Poyntz: J. Anat., 100, 549-569 (1966). 